11 Abstract

12 Introduction

13 Materials and experimental methods

14 Results: Elastic behaviour of allanite at high-pressure

15 Results: Deformation mechanisms at the atomic scale

16 Discussion and conclusions

17 Acknowledgements

18 References

19 Figures/Tables

Running title: $\mathrm{H} P$ behavior of allanite 


\title{
Allanite at high pressure: effect of REE on the elastic behaviour of epidote-group minerals
}

\author{
${ }^{1}$ G. Diego Gatta, ${ }^{1}$ Sula Milani, ${ }^{1}$ Luca Corti, ${ }^{1}$ Davide Comboni, ${ }^{1}$ Paolo Lotti, \\ ${ }^{1}$ Marco Merlini, ${ }^{2}$ Hanns-Peter Liermann \\ ${ }^{1}$ Dipartimento di Scienze della Terra, Università degli Studi di Milano, \\ Via Botticelli 23, I-20133 Milano Italy \\ ${ }^{2}$ Photon Sciences, DESY, PETRA-III, Notkestrasse 85, D-22607, Hamburg, Germany
}

\section{Abstract}

The compressional behaviour of a natural allanite from Lago della Vecchia (upper Cervo valley, Italy) metagranitoids $\left[{ }^{A 1}\left(\mathrm{Ca}_{0.69} \mathrm{Fe}^{2+}{ }_{0.31}\right)_{\Sigma 1.00}{ }^{A 2}\left(\mathrm{Ca}_{0.46} \mathrm{Ce}_{0.24} \mathrm{La}_{0.12} \mathrm{Sm}_{0.02} \mathrm{Pr}_{0.05} \mathrm{Nd}_{0.09} \mathrm{Th}_{0.02}\right)_{\Sigma 1.00}\right.$ ${ }^{M 1}\left(\mathrm{Al}_{0.65} \mathrm{Fe}^{3+}{ }_{0.34} \mathrm{Ti}_{0.02}\right)_{\Sigma 1.01}{ }^{M 2}\left(\mathrm{Al}_{0.99}\right)^{M 3}\left(\mathrm{Fe}^{3+}{ }_{0.54} \mathrm{Fe}^{2+}{ }_{0.36} \mathrm{Mg}_{0.06} \mathrm{Ti}^{4+}{ }_{0.02} \mathrm{Al}_{0.01}\right)_{\Sigma 0.99}$ Sil,Si2,Si3 $\left.\left(\mathrm{Si}_{2.80} \mathrm{Al}_{0.20}\right)_{\Sigma 3.00} \mathrm{O}_{11}(\mathrm{OH}, \mathrm{O})\right]$ has been investigated up to $16 \mathrm{GPa}$ (at $298 \mathrm{~K}$ ) by means of in-situ synchrotron single-crystal X-ray diffraction. Experiments have been conducted under hydrostatic conditions, using a diamond anvil cell and the mix methanol:ethanol:water=16:3:1 (up to $10 \mathrm{GPa}$ ) and neon (up to $16 \mathrm{GPa}$ ) as pressuretransmitting media. No phase transition has been observed within the pressure-range investigated; data collected in decompression prove that, at least up to $16 \mathrm{GPa}$ (at 298 $\mathrm{K})$, the deformation mechanisms are fully reversible. A third-order Birch-Murnaghan Equation of State $(\mathrm{BM}-\mathrm{EoS})$ was fitted to the $P-V$ data (up to $10 \mathrm{GPa}$ ), giving: $V_{0}=$ $470.2(2) \AA^{3}, K_{\mathrm{P} 0, \mathrm{~T} 0}=131(4) \mathrm{GPa}$ and $K^{\prime}=1.9(8)$. The evolution of the lattice parameters with pressure shows a slight anisotropic compression pattern, with $K_{\mathrm{P} 0, \mathrm{~T} 0}(a): K_{\mathrm{P} 0, \mathrm{~T} 0}(b): K_{\mathrm{P} 0, \mathrm{~T} 0}(c)=1.24: 1.52: 1$. The monoclinic $\beta$-angle decreases monotonically with pressure, with: $\beta_{\mathrm{P}}\left(^{\circ}\right)=\beta_{\mathrm{P} 0}-0.0902(4) P \quad\left(R^{2}=0.997\right.$, with $P$ in $\mathrm{GPa})$.

The main deformation mechanisms at the atomic scale are described based on a series of structure refinements at different pressures. A comparison between the compressional behavior of allanite, epidote and clinozoisite is carried out.

68 Keywords: allanite, epidote, synchrotron single-crystal X-ray diffraction, highpressure, compressibility. 


\section{Introduction}

Allanite is a sorosilicate and a member of the epidote group, with general crystal formula $A(1) A(2) M(1) M(2) M(3)\left(\mathrm{SiO}_{4}\right)\left(\mathrm{Si}_{2} \mathrm{O}_{7}\right) \mathrm{O}(\mathrm{OH})$, where the $A(1)$ and $A(2)$ are sites with coordination number $\mathrm{CN}>6$ and mainly occupied by $\mathrm{Ca}$, and $M(1), M(2)$ and $M(3)$ are octahedral sites $(\mathrm{CN}=6)$ mainly occupied by $\mathrm{Al}$ and $\mathrm{Fe}^{3+}$ (Dollase 1971; Franz and Liebscher 2004; Armbruster et al. 2006). All the members of the epidote group are monoclinic in symmetry, with structure topology consistent with the space group $P 2_{1} / m$, although possible symmetry reduction in some epidotes (to $P m, P 2{ }_{1}$ or $P \overline{1})$ has been suggested as effect of cation ordering (Franz and Liebscher 2004). The structure of the epidote group minerals has single silicate tetrahedra $\left(\mathrm{SiO}_{4}\right)$, double silicate tetrahedra $\left(\mathrm{Si}_{2} \mathrm{O}_{7}\right)$, and continuous chains of $M \mathrm{O}_{6}$ and $M \mathrm{O}_{4}(\mathrm{OH})_{2}$ octahedra (parallel to the $b$-axis) as main building-block units. The octahedra are bridged by single $\mathrm{SiO}_{4}$ and double $\mathrm{Si}_{2} \mathrm{O}_{7}$ tetrahedral groups, in a configuration as that shown in (Fig. 1). Clinozoisite (ideally ${ }^{A l, A 2} \mathrm{Ca}_{2}{ }^{M 1, M 2, M 3} \mathrm{Al}_{3}\left(\mathrm{SiO}_{4}\right)\left(\mathrm{Si}_{2} \mathrm{O}_{7}\right) \mathrm{O}(\mathrm{OH})$ ) can be considered as the reference structure of the epidote group minerals, in which the three independent octahedral $M$ sites $(M 1, M 2$ and $M 3)$ are fully occupied by $\mathrm{Al}$ and the two independent $A$ sites ( $A 1$ and $A 2$ ) are occupied by Ca. The complex crystalchemistry of the epidote group led the Commission of the International Mineralogical Association to divide it into three subgroups (Armbruster et al. 2006). The allanite subgroup contains rare-earth elements (REE) rich minerals, typified by the eponymous mineral "allanite". The crystal chemistry of the allanite subgroup members may be derived from that of clinozoisite, by homovalent substitutions and one coupled heterovalent substitution, as follows:

${ }^{A 2}(\mathrm{REE}){ }^{3+}+{ }^{M 3} \mathrm{M}^{2+} \rightarrow{ }^{A 2} \mathrm{Ca}^{2+}+{ }^{M 3} \mathrm{M}^{3+}$.

In this light, the (cationic) site population is represented by: $A 1=\mathrm{M}^{2+}, A 2=\mathrm{M}^{3+}, M 1$ $=\mathrm{M}^{3+}, M 2=\mathrm{M}^{3+}$, and $M 3=\mathrm{M}^{2+}$, and the general formula of allanite is:

${ }^{A 1}(\mathrm{Ca})^{A 2}\left(\mathrm{REE}^{3+}\right)^{M 1, M 2}(\mathrm{Al})_{2}{ }^{M 3}\left(\mathrm{Fe}^{2+}\right)\left(\mathrm{SiO}_{4}\right)\left(\mathrm{Si}_{2} \mathrm{O}_{7}\right) \mathrm{O}(\mathrm{OH})$ (Dollase 1971; Gieré and Sorensen 2004; Armbruster et al. 2006).

Epidotes mainly occur in low-grade metamorphic rocks $\left(250-400^{\circ} \mathrm{C}, 1-2\right.$ kbars). However, Poli and Schmidt (1998) showed that epidotes are stable over a wide range of pressure and temperature in continental and oceanic crust. Magmatic epidotes were also reported and described by Schmidt and Poli (2004). A series of studies showed how the stability of epidote group minerals is not only influenced by 
103 pressure and temperature, but also by the $\mathrm{Al} / \mathrm{Fe}^{3+}$ ratio, oxygen fugacity, fluid 104 composition and solution pH (e.g., Holdaway 1972; Liou 1973; Bird and Helgeson 105 1980; Bird et al. 1988; Klemd 2004). In addition, a series of in-situ high-pressure $106(\mathrm{H} P)$ and high-temperature $(\mathrm{H} T)$ experiments have been devoted to epidote group 107 minerals, and in particular to clinozoisite and epidote sensu stricto, in order to derive 108 volume and axial compressibility or thermal expansion (e.g., Catti et al. 1988; 109 Holland et al. 1996; Pawley et al. 1996; Comodi and Zanazzi 1997; Franz and 110 Liebscher 2004; Liebscher 2004; Gatta et al. 2010, 2011a, 2011b; Qin et al. 2016), 111 along with $P$ - or $T$-induced deformation mechanisms at the atomic scale (e.g., Comodi 112 and Zanazzi 1997; Gatta et al. 2010, 2011a). However, to the best of our knowledge, 113 no experiments have so far been devoted to the behaviour of allanite at non-ambient 114 conditions by in-situ experiments. Consequently, bulk and axial compressibilities or 115 thermal expansion coefficients of this mineral are completely unknown, and the role 116 played by the REE replacing $\mathrm{Ca}$ at the $A$ sites, or the occurrence of $\mathrm{Fe}^{2+}$ at the 117 octahedral $M$ sites, is still obscure. In this light, the aim of this study is the 118 investigation of the $\mathrm{H} P$-behavior of a natural allanite, from Lago della Vecchia (upper 119 Cervo valley, Italy), by in-situ synchrotron single-crystal diffraction with a diamond 120 anvil cell, in order to: provide reliable thermodynamic parameters for petrologic 121 modeling, report any potential $P$-induced phase transition and describe the main 122 deformation mechanisms at the atomic scale via single-crystal structure refinements. 123 A comparison between the compressional parameters of allanite and those of epidote 124 sensu stricto and clinozoisite is carried out. 


\section{Materials and experimental methods}

129 Natural single-crystals of allanite from Lago della Vecchia (upper Cervo valley, Italy)

130 metagranitoids were used in this study. The host rock is characterized by

131 heterogenous deformation due to stain partitioning (Corti et al. 2017) during 132 development of HP-LT blueschist-facies dominant fabric, which represent a re133 equilibration following the metamorphic peak in the eclogite facies, under thermally 134 depressed conditions (Corti et al. 2018). Chemical microanalyses in wavelength135 dispersive mode (EPMA-WDS) were performed on a series of optically homogeneous 136 sub-millimetric crystals, using a JEOL JXA-8200 microprobe at the Earth Sciences 137 Department, University of Milano. The system was operated using an accelerating 138 voltage of $15 \mathrm{kV}$, a beam current of $5 \mathrm{nA}$, a beam diameter of $5 \mu \mathrm{m}$, and a counting 139 time of $30 \mathrm{~s}$ on the peaks and $10 \mathrm{~s}$ on the backgrounds. A series of natural and 140 synthetic standards were used. The raw data were corrected for matrix effects using 141 the protocol implemented in the JEOL suite of programs. The crystals of allanite, 142 selected for this study, were found to be compositionally homogeneous. The average 143 unit-formula, based on more than 40 point-analyses and calculated following the 144 protocol recommended by IMA Commission (Armbruster et al. 2006), on the basis of 13 oxygen atoms, is:

$146{ }^{A 1}\left(\mathrm{Ca}_{0.69} \mathrm{Fe}^{2+}{ }_{0.31}\right)_{\Sigma 1.00}{ }^{A 2}\left(\mathrm{Ca}_{0.46} \mathrm{Ce}_{0.24} \mathrm{La}_{0.12} \mathrm{Sm}_{0.02} \mathrm{Pr}_{0.05} \mathrm{Nd}_{0.09} \mathrm{Th}_{0.02}\right)_{\Sigma 1.00}$ ${ }^{M 1}\left(\mathrm{Al}_{0.65} \mathrm{Fe}^{3+}{ }_{0.34} \mathrm{Ti}_{0.02}\right)_{\Sigma 1.01}{ }^{M 2}\left(\mathrm{Al}_{0.99}\right)^{M 3}\left(\mathrm{Fe}^{3+}{ }_{0.54} \mathrm{Fe}^{2+}{ }_{0.36} \mathrm{Mg}_{0.06} \mathrm{Ti}^{4+}{ }_{0.02} \mathrm{Al}_{0.01}\right)_{\Sigma 0.99}$ ${ }^{S i 1, S i 2, S i 3}\left(\mathrm{Si}_{2.80} \mathrm{Al}_{0.20}\right)_{\Sigma 3.00} \mathrm{O}_{11}(\mathrm{OH}, \mathrm{O})$. Further details pertaining to experimental protocols and EPMA-WDS data statistics are given in Corti et al. (2019).

High-pressure synchrotron X-ray single-crystal diffraction experiments were 152 with an energy of $42.7 \mathrm{keV}(0.2904 \AA$ wavelength) were used, with a focusing spot of $153 \sim 8.5(\mathrm{H}) \times 1.8(\mathrm{~V}) \mu \mathrm{m}^{2}$ originating from a compound refractive lenses (CRL) system 154 consisting of 110 Be lenses with a radius of $50 \mu \mathrm{m}(400 \mu \mathrm{m}$ beam acceptance $)$ and a 155 focal length of $1,221 \mathrm{~mm}$. Two prismatic single-crystals of allanite $(\sim 50 \times 50 \times 15$ $156 \mu^{3}$ ) were selected for the HP experiments, loaded, respectively, in two symmetric 157 diamond anvil cells (DAC), equipped with Boehler-Almax design diamonds/seats 158 with a $70^{\circ}$ opening and $300-\mu \mathrm{m}$ culets size. For the first DAC, a $250-\mu \mathrm{m}$-thick 159 rhenium gasket was pre-indented to $50 \mu \mathrm{m}$ and then drilled with $150 \mu \mathrm{m}$ hole, in 160 which the crystal of allanite along with some calibrated ruby spheres (for pressure 
161 determination, according to Mao et al. 1986) were placed. Neon was used as 162 hydrostatic pressure transmitting medium (Klotz et al. 2009). For the second DAC, a $163250-\mu \mathrm{m}$-thick steel gasket was pre-indented to $60 \mu \mathrm{m}$ and then drilled with $150 \mu \mathrm{m}$ 164 hole, in which the crystal of allanite and ruby micro-spheres were located. In this case, 165 the methanol:ethanol:water $=16: 3: 1 \mathrm{mix}$ was used as hydrostatic $P$-transmitting fluid 166 up to $10 \mathrm{GPa}$ (Angel et al. 2007). For both the experiments, pressure was increased 167 with an automated pressure-driven system and measured with the online 168 ruby/alignment system. Diffraction images were acquired on a PerkinElmer XRD 1691621 flat panel detector, using an in-house script for collecting step-scan diffraction 170 images. Sample to detector distance $(402.34 \mathrm{~mm})$ was calibrated using a $\mathrm{CeO}_{2}$ 171 standard (NIST 674a). The diffraction images were then converted to conform to the 172 "Esperanto" format of the program CrysAlis (Rigaku - Oxford Diffraction 2018; 173 Rothkirch et al. 2013). The diffraction data were first collected with the crystals in the $174 \mathrm{DAC}$ and without any $P$-medium (i.e. ambient pressure). A pure $\omega$-scan $\left(-33^{\circ} \leq \omega \leq\right.$ $175+33^{\circ}$ ), with a step size of $0.5^{\circ}$ and an exposure time of $0.5 \mathrm{~s} / \mathrm{frame}$, was used during 176 data collection. X-ray diffraction peaks were then indexed and their intensities were 177 integrated and corrected for Lorentz-polarization (Lp) effects, using the CrysAlis 178 package. Scaling and correction for absorption (due to the DAC components) was 179 applied by the semi-empirical $A B S P A C K$ routine implemented in CrysAlis. The 180 reflection conditions were consistent with those of the space group $P 2{ }_{1} / m$. HP data for 181 the experiments with methanol:ethanol:water mix as $P$-fluid were collected up to $\sim 8.5$ $182 \mathrm{GPa}$; those pertaining to the experiment with neon as $P$-transmitting medium up to $183 \sim 16.3 \mathrm{GPa}$ (the hydrostatic limit of neon, according to Klotz et al. 2009). No evidence 184 of phase transitions was observed within the $P$-range investigated. Data collected in 185 decompression proved that allanite behaves elastically at least up to $16 \mathrm{GPa}$ (at 298 $186 \mathrm{~K})$ (Table 1) under hydrostatic conditions. The unit-cell parameters of allanite with $P$, 187 based on the two different ramps (i.e., in methanol:ethanol:water mix and in neon) are 188 listed in Table 1.

189 The isotropic structure refinements, based on the intensity data of the two HP 190 ramps, were conducted using the software SHELXL97 (Sheldrick 1997, 2008), 191 starting from the structure model of Dollase (1971) and Bonazzi et al. (2009), in the 192 space group $P 2{ }_{1} / \mathrm{m}$. To reduce the number of variables to refine, and considering the 193 average chemical composition of the allanite of this study, the atomic sites were 
modelled as follows: the $A 1$ and $A 2$ sites were modelled with a mixed $(\mathrm{Ca}+\mathrm{Ce}) \mathrm{X}$ ray scattering curve, and the fraction of $\mathrm{Ca} v s$. Ce were refined; the $M 1$ and $M 2$ octahedral sites as populated by $\mathrm{Al}$ only and the $M 3$ site as populated by $(\mathrm{Fe}+\mathrm{Al})$, and the fraction Fe vs. Al were refined; the three independent tetrahedral sites (i.e., $\mathrm{Sil}$, Si2 and Si3) were modelled as fully occupied by Si. For all the refinements, convergence was rapidly achieved and, at the end of the last cycles of refinement, no significant correlation was observed in the variance-covariance matrix of the refined parameters. The principal statistical parameters of the structure refinements are listed in Table 2. Atomic coordinates and site occupancies of selected structure refinements are given in Table S1. Bond distances and other relevant structural parameters are reported in Tables $\mathrm{S} 2$ and 3.

\section{Results: Elastic behaviour of allanite at high-pressure}

The evolution of the lattice parameters of allanite with pressure is shown in Fig. 2 and Fig. S1, which shows that no phase transition or change of the deformation mechanisms occur within the $P$-range investigated (i.e., at least up to $16 \mathrm{GPa}$ at 298 K). A second- and a third-order Birch-Murnaghan Equation of State (BM-EoS) (Birch 1947; Angel 2000) were fitted to the $P-V$ data pertaining to the experiment with methanol:ethanol:water mix as $P$-transmitting fluid (i.e., the most populated $P$-ramp), using the EOS-FIT program (by RJ Angel, www.rossangel.com). This isothermal EoS is based on the assumption that the high-pressure strain energy in a solid can be expressed as a Taylor series in the Eulerian finite strain, defined as $f e=\left[\left(V_{0} / V\right)^{2 / 3}-\right.$ $1] / 2$, and allows to obtain the bulk modulus $\left(K_{\mathrm{P} 0, \mathrm{~T} 0}=V(\partial P / \partial V)_{\mathrm{T} 0}=\beta^{-1} \mathrm{P} 0, \mathrm{~T} 0\right.$, where $\beta_{\mathrm{P} 0, \mathrm{~T} 0}$ is the volume compressibility coefficient at room conditions) and its $P$ derivatives. Expansion in the Eulerian strain polynomial has the following form:

$P(f e)=3 K_{\mathrm{P} 0, \mathrm{~T} 0} f e(1+2 f e)^{5 / 2}\left\{1+3 / 2\left(K^{\prime}-4\right) f e+3 / 2\left[K_{\mathrm{P} 0, \mathrm{~T} 0} K^{\prime \prime}+\left(K^{\prime}-4\right)\left(K^{\prime}-3\right)+35 / 9\right]\right.$ $\left.f e^{2}+\ldots\right\}$, where $K^{\prime}=\partial K_{\mathrm{P} 0, \mathrm{~T} 0} / \partial P$ and $K^{\prime \prime}=\partial^{2} K_{\mathrm{P} 0, \mathrm{~T} 0} / \partial P^{2}$.

The BM-EoS parameters, simultaneously refined using the data weighted by their uncertainties in $P$ and $V$, are listed in Table 4. Using a second-order BM-EoS fit, convergence is achieved with: $V_{0}=470.6(2) \AA^{3}$ and $K_{\mathrm{P} 0, \mathrm{~T} 0}=122(1) \mathrm{GPa}$. A better fit is obtained using a third-order BM-EoS with: $V_{0}=470.2(2) \AA^{3}, K_{\mathrm{P} 0, \mathrm{~T} 0}=131(4) \mathrm{GPa}$ and $K^{\prime}=1.9(8)$. The use of a third-order BM-EoS in energy, to model the compressional behaviour of allanite, is also corroborated by the evolution of the Eulerian finite strain 
vs. "normalized stress" plot (fe-Fe plot, with $F e=P /\left[3 f e(1+2 f e)^{5 / 2}\right]$; Angel 2000), shown in Fig. 3: the weighted linear regression through the data points yields $\mathrm{Fe}(0)=$ 131(2) GPa as intercept values and the (negative) slope of the regression line gives rise to a $K^{\prime}$ value of 1.9(6), in good agreement with the third-order BM-EoS fit.

The confidence ellipses at $68.3 \%$ level $\left(\Delta \chi^{2}=2.30, \pm 1 \sigma\right), 95.4 \%$ level $\left(\Delta \chi^{2}\right.$ $232=6.17, \pm 2 \sigma)$ and $99.7 \%$ level $\left(\Delta \chi^{2}=11.8, \pm 3 \sigma\right)$ were calculated starting from the 233 variance-covariance matrix of $K_{\mathrm{P} 0, \mathrm{~T} 0}$ and $K^{\prime}$ obtained from the least-square procedure 234 (third-order BM-EoS fit previously described; Angel 2000). The ellipses are strongly 235 elongated with negative slope (Fig. 4), showing a negative correlation of the 236 parameters $K_{\mathrm{P} 0, \mathrm{~T} 0}$ and $K^{\prime}$.

The evolution of the lattice parameters with pressure shows a slight anisotropic compressional pattern. The "axial bulk moduli", calculated with a second-order "linearized" BM-EoS (Angel 2000 for details), are: $K_{\mathrm{P} 0, \mathrm{TO}}(a)=114(2) \mathrm{GPa}$ for the $a$ axis, $K_{\mathrm{P} 0, \mathrm{~T} 0}(b)=140(4) \mathrm{GPa}$ for the $b$-axis, and $K_{\mathrm{P} 0, \mathrm{~T} 0}(c)=92(1) \mathrm{GPa}$ for the $c$-axis, with a general anisotropic compressional scheme:

$242 K_{\mathrm{P} 0, \mathrm{~T} 0}(a): K_{\mathrm{P} 0, \mathrm{~T} 0}(b): K_{\mathrm{P} 0, \mathrm{~T} 0}(c)=1.24: 1.52: 1$ (Table 4). The second-order BM-EoS fits provide the best figure of merit. The monoclinic $\beta$-angle decreases linearly with pressure, with: $\beta_{\mathrm{P}}\left({ }^{\circ}\right)=\beta_{\mathrm{P} 0}\left({ }^{\circ}\right)-0.0902(4) P \quad\left(R^{2}=0.997\right.$, with $P$ in GPa) (Fig. 2 and $\mathrm{S} 1)$.

Magnitude and orientation of the principal unit-strain coefficients between room pressure and the maximum $P$ achieved (i.e., $\Delta P=8.51 \mathrm{GPa}$, ramp in methanol:ethanol:water mix), derived on the basis of the finite Eulerian strain tensor, were calculated with the Win_Strain software (by RJ Angel, www.rossangel.com).

250 The following Cartesian axial system was chosen: $x / / a^{*}$ and $y / / b$. The strain ellipsoid 251 is oriented with the mid axis ( $\varepsilon 2)$ parallel to the $b$-axis, and the major $(\varepsilon 1)$ and minor 252 (ع3) axes lying in the (010)-plane: $\varepsilon 1$ describes an angle of 136.6(2) ${ }^{\circ}$ from $a$ (and thus $25322.3(2)^{\circ}$ from $c$ ), as shown in Fig. 1. The elastic behaviour of allanite based on the 254 unit-strain coefficients between 0.0001 and $8.51 \mathrm{GPa}$ is more anisotropic if compared 255 to that deduced only along the principal crystallographic directions, being $\varepsilon 1=$ $2560.02849(5), \varepsilon 2=-0.0192(5)$, and $\varepsilon 3=-0.01306(8) \mathrm{GPa}^{-1}$, with the resulting anisotropic 257 scheme: $\varepsilon 1: \varepsilon 2: \varepsilon 3=2.18: 1.47: 1$. 

experiment was mainly aimed to demonstrate that, at least up to $16 \mathrm{GPa}$, allanite is still crystalline. Thus, Ne-data were not used for the compressional analysis.

\section{Results: Deformation mechanisms at the atomic scale}

The mechanisms at the atomic scale that govern the anisotropic compression of the allanite structure can be described in terms of intra- and inter-polyhedral rearrangement in response to the applied pressure. Intra-polyhedral deformations are usually described in terms of compression of the bond distances or by distortion (i.e., with or without bond-distances compression), inter-polyhedral rearrangements in terms of polyhedral tilting.

If we consider the $P$-induced atomic displacements in allanite structure, the oxygen sites $O 8$ and $O 9$ show the most pronounced displacements from their positions refined at $0.0001 \mathrm{GPa}$. $O 9$ is the bridging oxygen between the $T 1$ and $T 2$ tetrahedra, describing the angle $T 1-O 9-T 2$ of $\sim 145.5^{\circ}$ at $0.0001 \mathrm{GPa}$, which decreases to $\sim 140.4^{\circ}$ at $8.5 \mathrm{GPa}$ (Table $\mathrm{S} 2$ ); the difference is remarkable, if we consider the $P$ range. This tilting mechanism, governed by the displacement of the $O 9$ site, affects the shape of the 5-membered rings of polyhedra (M2-T3-M2-T2-T1, Fig. 1), confining the cavities in which the $A 1$ site lies: the contraction of the $\mathrm{O} 3 \leftrightarrow \mathrm{O} 1, \mathrm{O} 6 \leftrightarrow \mathrm{O} 1$ and $\mathrm{O} 9 \leftrightarrow \mathrm{O} 5$ "diameters" is significatly different, being respectively $\sim 0.09, \sim 0.06$, and $\sim 0.03 \AA$ within the $P$-range $0.0001-8.5 \mathrm{GPa} . O 9$ is also bonded to the $A 1$ site, and the displacement of the $O 9$ leads to a change of the A1-O9 bond length: $\sim 3.095 \AA$ at $0.0001 \mathrm{GPa}$ and $\sim 3.074 \AA$ at $8.5 \mathrm{GPa}$ (Table S2).

$O 8$ is the bridging oxygen between the $T 2$ and $M 3$ polyhedra. The T2-O8-M3 angle is $\sim 130.3^{\circ}$ at $0.0001 \mathrm{GPa}$ and drastically decreases to $\sim 123.0^{\circ}$ at $8.5 \mathrm{GPa}$ (Table 283 S2). The displacement of the $O 8$ site, and the aforementioned and co-related 284 polyhedral tilting, affect the shape evolution with $P$ of the 8 -membered rings of 285 polyhedra (M2-T3-M3-T2-M2-T3-M3-T2), in which the A2 site lies (Fig. 1). More specifically, the $\mathrm{O} 8 \leftrightarrow \mathrm{O} 8$ "diameter" is pronouncedly shortened by $\sim 0.30 \AA$ at 8.51

$287 \mathrm{GPa}$ and, in the same $P$-range, the $\mathrm{O} 3 \leftrightarrow \mathrm{O} 3, \mathrm{O} 6 \leftrightarrow \mathrm{O} 10$ and $\mathrm{O} 6 \leftrightarrow \mathrm{O} 6$ diameters are 288 shortened by $\sim 0.20 \AA, \sim 0.15 \AA$, and $\sim 0.16 \AA$, respectively (Fig. 1, Table 3 ). This leads 289 to a more rectangular-edged ring at high pressure, affecting mainly the length of the unit-cell edge parallel to the $c$-axis. 
The aforementioned polyhedral tilting mechanisms are coupled with the intrapolyhedral distortion and compression in response to the applied pressure, which are energetically more costly and, therefore, less pronounced at low- or mid- $P$ regimes.

294 The evolution of the intra-polyhedral bond distances and angles shows that, within the $295 P$-range investigated, tetrahedra behaves as quasi-rigid units at a first approximation 296 (with minor bond-distances shortening or polyhedral distortion), octahedra are more 297 affected by compression and distortion (though not dramatic), whereas the large $A 1-$ and A2-polyhedra are the most affected by distortion and bond-distances shortening in response to the applied pressure (Table S2). However, the quality of the structural data at high pressure allow us to observe a different behaviour among the three independent tetrahedra: $T 1$ and $T 2$ are essentially rigid (i.e., difference in their bong lengths of the same order of the e.s.ds), but $T 3$ tends to deform significantly, in particular in response to the shortening of the $T 2-O 2$ distance of about $0.03 \AA$ (with $\Delta P=8.5 \mathrm{GPa}$; Table S2). Even among the three independent octahedra, we can observe different magnitude of (compression+distortion): within the $P$-range investigated, the maximum shortening of the intra-polyhedral bond lengths is $\sim 0.04 \AA$ for the $M 2$ octahedron, $\sim 0.06 \AA$ for the $M 1$ octahedron, and $\sim 0.10 \AA$ for the $M 3$ octahedron. Therefore, the Fe-rich M3 octahedron is the most distorted one under hydrostatic compression, even in response to the pronounced T2-O8-M3 compression described above.

One open question concerns the role played by the H-bonding scheme on the $P$ -

312 induced structure evolution of allanite. In allanite structure (as in all the epidote-group 313 members), there is only one unique $H$ site. $O 10$ acts as donor and $O 4$ acts as acceptor 314 of the H-bond (i.e., O1O-H..O4); O4 is the oxygen co-shared by two MI and one M3 315 octahedra and $O 10$ is the bridging oxygen between the edge-sharing M2 octahedra. 316 Proton, donor and acceptor are confined in the 5-membered ring. It is impossible to refine the $H$ site coordinates in the $\mathrm{HP}$ structure refinements. However, we can intuitively consider that the H-bonding geometry can explain why in the 5-membered ring the major deformation mechanism acts on one side through the T1-O9-T2 tilting, as the $T 1$ and $T 2$ tetrahedra are unaffected by the H-bonding. As a consequence, the $O 3 \leftrightarrow O 1$ shortening is more pronounced than the $O 6 \leftrightarrow O 1$ and $O 9 \leftrightarrow O 5$ ones (Fig. 1, 
To the best of our knowledge, this is the first study on the compressional behaviour of allanite, here described on the basis of in-situ synchrotron single-crystal diffraction data. The experimental findings of this study confirm that allanite preserves its crystallinity and behaves elastically at least up to $16 \mathrm{GPa}$ (at $298 \mathrm{~K}$ ), under hydrostatic compression (Table 2).

The Eulerian unit-strain ellipsoid, calculated between 0.0001 and $8.51 \mathrm{GPa}$, confirms that the lowest and the highest compression directions lie on the (010)-plane, as shown in Fig. 1: the softest direction (ع1) describes an angle of $136.6(2)^{\circ}$ from [100], and as a consequence the stiffest direction ( $\varepsilon 3)$ describes an angle of $46.6(2)^{\circ}$ from [100]. A recalculation of magnitude and orientation of the compressional unitstrain ellipsoids of epidote with $0.74 \mathrm{Fe}$ a.p.f.u. (based on the data of Gatta et al. $2011 \mathrm{~b}$, for $\Delta P=8.30 \mathrm{GPa}, P_{\min }=0.0001 \mathrm{GPa}$ ), of epidote with $0.79 \mathrm{Fe}$ a.p.f.u. (based on the data of Qin et al. 2016, for $\Delta P=9.70 \mathrm{GPa}, P_{\min }=0.0001 \mathrm{GPa}$ ), and clinozoisite with $0.40 \mathrm{Fe}$ a.p.f.u. (based on the data of Qin et al. 2016, for $\Delta P=8.80 \mathrm{GPa}, P_{\min }=$ $0.0001 \mathrm{GPa}$ ), was done, using the same Cartesian axial system and strain definition (i.e., Eulerian) adopted for allanite:

1) in epidote with $0.79 \mathrm{Fe}$ a.p.f.u., the stiffest direction $\left(\varepsilon 3=-0.0232(2) \mathrm{GPa}^{-1}\right)$ is parallel to [010], whereas the mid $\left(\varepsilon 2=-0.0236(3) \mathrm{GPa}^{-1}\right)$ and the softest $\left(\varepsilon 1=-0.0258(8) \mathrm{GPa}^{-1}\right)$ directions lie on $(010)$, with the softest one describing an angle of $63(5)^{\circ}$ with [100]; anisotropic compressional scheme: $\varepsilon 1: \varepsilon 2: \varepsilon 3=1.11: 1.01: 1$, i.e. there is an almost circular section of the ellipsoid in which $\varepsilon 2$ and $\varepsilon 3$ are dispersed; the monoclinic $\beta$ angle decreases monotonically with $P$ (Qin et al. 2016);

2) in epidote with $0.74 \mathrm{Fe}$ a.p.f.u., the stiffest direction $\left(\varepsilon 3=-0.01646(8) \mathrm{GPa}^{-}\right.$ $\left.{ }^{1}\right)$ is parallel to [010], whereas the mid $\left(\varepsilon 2=-0.01978(8) \mathrm{GPa}^{-1}\right)$ and the softest $\left(\varepsilon 1=-0.02352(6) \mathrm{GPa}^{-1}\right)$ directions lie on (010), with the softest one describing an angle of $126.7(8)^{\circ}$ with [100]; anisotropic compressional scheme: $\varepsilon 1: \varepsilon 2: \varepsilon 3=1.43: 1.20: 1$; the monoclinic $\beta$ angle decreases monotonically with $P$ (Gatta et al. 2011b);

3) in clinozoisite (0.40 Fe a.p.f.u.), the stiffest direction $\left(\varepsilon 3=-0.0138(2) \mathrm{GPa}^{-}\right.$ $\left.{ }^{1}\right)$ is parallel to [010], whereas the mid $\left(\varepsilon 2=-0.0145(2) \mathrm{GPa}^{-1}\right)$ and the softest $\left(\varepsilon 1=-0.0234(1) \mathrm{GPa}^{-1}\right)$ directions lie on $(010)$, with the softest one 
describing an angle of $174(1)^{\circ}$ with [100]; anisotropic compressional scheme: $\varepsilon 1: \varepsilon 2: \varepsilon 3=1.70: 1.05: 1$; the monoclinic $\beta$ angle decreases monotonically with $P$ (Qin et al. 2016).

360 On this basis, some general conclusions can be drawn:

The stiffest direction can easily assume a different orientation in response to small compositional changes, due to the modest anisotropy observed $(\varepsilon 2: \varepsilon 3=1.01: 1$ and

1) The softest directions in allanite, epidote(s) and clinozoisite lie all on (010);

2) The stiffest directions in epidote and clinozoisite are consistently oriented parallel to [010], whereas in allanite it lies on (010) (i.e., $\varepsilon 3 \angle[100]=$ $\left.46.6(2)^{\circ}\right)$;

3) The compressional schemes of allanite, epidote(s) and clinozoisite are significantly different: more anisotropic in allanite $(\varepsilon 1: \varepsilon 2: \varepsilon 3=2.18: 1.47: 1)$, less in epidote $(\varepsilon 1: \varepsilon 2: \varepsilon 3=1.43: 1.20: 1$ with $0.74 \mathrm{Fe}$ a.p.f.u, and $\varepsilon 1: \varepsilon 2: \varepsilon 3=$ 1.11:1.01:1 with $0.79 \mathrm{Fe}$ a.p.f.u) and clinozoisite $(\varepsilon 1: \varepsilon 2: \varepsilon 3=1.70: 1.05: 1)$.

4) Concerning the joint epidote-clinozoisite, it is observable a drastic rotation of the unit-strain ellipsoid in response to the different Fe content: the softest direction describes an angle from [100] of $174(1)^{\circ}$ in clinozoisite with $0.40 \mathrm{Fe}$ a.p.f.u., of $126.7(8)^{\circ}$ in epidote with $0.74 \mathrm{Fe}$ a.p.f.u. and of $63(5)^{\circ}$ in epidote with $0.79 \mathrm{Fe}$ a.p.f.u., i.e. the lower the $\mathrm{Fe}$ content, the higher the angle $\varepsilon 1 \angle[100]$.

1.20:1 in epidote, 1.05:1 in clinozoisite, and 1.47:1 in allanite).

Our data on allanite show that the inter- and intra-polyhedral mechanisms, described on the basis of the structure refinements at high pressure, are not sufficient to explain, unambiguously, magnitude and orientation of the unit-strain ellipsoid. In this light, only some general considerations can be done:

1) The Eulerian unit-strain ellipsoid shows that the stiffest direction ( 83 ) lies on (010), it is perpendicular to the softest one and is likely governed by the presence of (almost uncompressible) edge-sharing M3-M1-M3 clusters of octahedra (almost parallel to $\varepsilon 3$ ), connected to the A2 sites (Fig. 1, Table S2).

2) The intermediate one ( $\varepsilon 2)$ is parallel to [010]. The compression of the allanite structure along [010] is likely hindered by the presence of the (infinite) edge-sharing $\mathrm{MlO}_{6}$ octahedral chains, running along [010] 

the shortening along the chain direction can only occur through intrapolyhedral deformation, by homogeneous or non-homogeneous (i.e., polyhedral distortion) bond-distances compression. The most compressible direction ( $\varepsilon 1$, as defined above) in allanite structure lies also on (010). Tilting and (compression+distortion) of the polyhedra, described above, generate, in turns, the deformations of the 5- and 8-membered rings of polyhedra. The most pronounced compression directions of the rings (represented e.g. by the diameters $O 3 \leftrightarrow O 1$ of the 5 -membered ring and by $O 8 \leftrightarrow O 8$ of the 8 -membered ring) can play an important role on the orientation of $\varepsilon 1$ (Fig. 1, Table S2). bulk moduli" along the three crystallographic axes, all obtained on the basis of a second-order BM-EoS fit (as the truncation to second-order provide the best figures of merit), is: $K_{\mathrm{P} 0, \mathrm{T0}}(a): K_{\mathrm{P} 0, \mathrm{~T} 0}(b): K_{\mathrm{P} 0, \mathrm{~T} 0}(c)=1.24: 1.52: 1$ in allanite, $K_{\mathrm{T} 0}(a): K_{\mathrm{T} 0}(b): K_{\mathrm{T} 0}(c)=$ 1.13:1.48:1 in epidote with 0.74 Fe a.p.f.u. (recalculated from Gatta et al. 2011b) and $K_{\mathrm{T} 0}(a): K_{\mathrm{T} 0}(b): K_{\mathrm{T} 0}(c)=1: 1.19: 1.04$ in epidote with 0.79 Fe a.p.f.u. (Qin et al. 2016), and $K_{\mathrm{P} 0, \mathrm{~T} 0}(a): K_{\mathrm{P} 0, \mathrm{~T} 0}(b): K_{\mathrm{P} 0, \mathrm{~T} 0}(c)=1: 1.81: 1.52$ in clinozoisite with $0.40 \mathrm{Fe}$ a.p.f.u. (Qin et al. 2016).

The bulk compression of allanite, epidote and clinozoisite is significantly 411 different (Fig. 2). Using a third-order BM-EoS, the following parameters are obtained: $412 K_{\mathrm{P} 0, \mathrm{~T} 0}=131(4) \mathrm{GPa}$ and $K^{\prime}=1.9(8)$ for allanite, $K_{\mathrm{P} 0, \mathrm{~T} 0}=111(3) \mathrm{GPa}$ and $K^{\prime}=7.6(7)$ for 413 epidote with $0.74 \mathrm{Fe}$ a.p.f.u. (Gatta et al. 2011b) and $K_{\mathrm{P} 0, \mathrm{~T} 0}=115(2) \mathrm{GPa}$ and $414 K^{\prime}=3.7(2)$ for epidote with $0.79 \mathrm{Fe}$ a.p.f.u. (Qin et al. 2016), and $K_{\mathrm{P} 0, \mathrm{~T} 0}=142$ (3) $\mathrm{GPa}$ 415 and $K^{\prime}=5.2$ (4) for clinozoisite with $0.40 \mathrm{Fe}$ a.p.f.u. (Qin et al. 2016). Epidote is the softest one, clinozoisite is the stiffest and allanite lies in between.

On the basis of a comparative analysis of the compressional behavior of 418 epidotes and clinozoisites reported in the literature, along with those obtained 419 experimentally in their study, Qin et al. (2016) concluded that increasing Fe content 420 reduces the bulk modulus and increases the first $P$-derivative (using the BM-EoS 421 formulation). This behavior was attributed to the differences in compression behavior 422 due to the addition of $\mathrm{Fe}$ at the $M 3$ site (replacing $\mathrm{Al}$ ) in the epidote structure. 
423 Additional in-situ HP Raman data collected by Qin et al. (2016) further suggest that 424 the difference in compressibility between epidote and clinozoisite is likely to the 425 different compressibility of $\mathrm{FeO}_{6-}$ and $\mathrm{AlO}_{6}$-octahedra, coordinated by the $M 3$ sites. 426 In allanite, the scenario is more complex: Fe and $\mathrm{Al}$ mainly populate the octahedral 427 sites (Fe occurs principally at the $M 3$ site, like in epidote), but a fraction of Al likely 428 replaces $\mathrm{Si}$ at the tetrahedral sites and, more important, Fe along with a series of other 429 LREE elements (mainly $\mathrm{Ce}$ and $\mathrm{La}$ ) replace $\mathrm{Ca}$ at the $A 1$ and $A 2$ sites. In this light, the 430 conclusion of Qin et al (2016), about the role played by iron content on the 431 compressional behavior, cannot be simplistically extended to allanite, as more 432 variables can influence the different behavior of allanite if compared to the other two 433 aforementioned members of the epidote group.

\section{Acknowledgements}

436 PETRA-III synchrotron facility (Hamburg, Germany) is acknowledged for provision 437 of beamtime at P02.2 beamline. G.D.G., S.M., L.C., D.C., P.L., M.M. acknowledge 438 the support of the Italian Ministry of Education (MIUR) through the project 439 “Dipartimenti di Eccellenza 2018-2022". W. Crichton and an anonymous reviewer 440 are thanked for the revision of the manuscript.

\section{References}

Angel RJ (2000) Equation of State. In: Hazen RM, Downs RT (eds) Hightemperature and high-pressure crystal chemistry. Reviews in Mineralogy and

446 Geochemistry, vol. 41, Mineralogical Society of America and Geochemical Society, 447 Washington, DC, pp 35-59.

Angel RJ, Bujak M, Zhao J, Gatta GD, Jacobsen SD (2007) Effective hydrostatic limits of pressure media for high-pressure crystallographic studies. J Appl Crystallogr 40:26-32.

Armbruster T, Bonazzi P, Akasaka M, Bermanec V, Chopin C, Gieré R, HeussAssbichler S, Liebscher A, Menchetti S, Pan Y, Pasero M (2006) Recommended nomenclature of epidote-group minerals. Eur J Mineral 18:551-567. 
epidote-feldspar mineral assemblages in geologic systems, I: thermodynamic analysis of phase relations in the system $\mathrm{CaO}-\mathrm{FeO}-\mathrm{Fe}_{2} \mathrm{O}_{3}-\mathrm{Al}_{2} \mathrm{O}_{3}-\mathrm{SiO}_{2}-\mathrm{H}_{2} \mathrm{O}-\mathrm{CO}_{2}$. Am J Science 280:907-941.

Bird DK, Cho M, Janik CJ, Liou JG, Caruso LJ (1988) Compositional, orderdisorder, and stable isotopic characteristics of Al-Fe epidote, state 2-14 drill hole, Salton Sea geothermal system. J Geophys Res 93(B11):13135-13144.

Bonazzi P, Holtstam D., Bindi L., P. Nysten, Capitani G.C. (2009) Multianalytical approach to solve the puzzle of an allanite-subgroup mineral from Kesebol, Västra Götaland, Sweden. Am Mineral 94: 121-134.

Catti M, Ferraris G, Ivaldi G (1988) Thermal behaviour of the crystal structure of strontian piemontite. Am Mineral 73:1370-1376.

Comodi P, Zanazzi PF (1997) The pressure behaviour of clinozoisite and zoisite. An X-ray diffraction study. Am Mineral 82:61-68.

Corti L, Alberelli G, Zanoni D, Zucali M (2017) Analysis of fabric evolution and metamorphic reaction progress at Lago della Vecchia-Valle d'Irogna, SesiaLanzo Zone, Western Alps. J Maps 13:521-533.

Corti L, Alberelli G, Zanoni D, Zucali M (2018) Tectonometamorphic evolution of the Lago della Vecchia metaintrusive and its country rocks, Sesia-Lanzo Zone, Western Alps. Ital J Geosci 137:188-207.

Corti L, Zanoni D, Gatta GD, Zucali M (2019) Shielding effect in allanite as tomantle carrier of LREE: strain, chemistry, and crystallographic constraints. Geology (under revision).

Dollase WA (1971) Refinement of the crystal structure of epidote, allanite and hancockite. Am Mineral 56:447-464.

Franz G, Liebscher A (2004) Physical and chemical properties of epidote minerals - An Introduction. In Franz G, Liebscher A (eds), Epidotes, Vol. 56, p. 1-81. Reviews in Mineralogy and Geochemistry, Mineralogical Society of America and Geochemical Society, Washington, U.S.A.

Gatta GD, Meven M, Bromiley G (2010) Effects of temperature on the crystal structure of epidote: a neutron single-crystal diffraction study at 293 and 1,070 K. Phys. Chem. Minerals 37:475-485.

Gatta G.D., Alvaro M., Bromiley G. (2011a) A low temperature X-ray single- 
crystal diffraction and polarised infra-red study of epidote. Phys. Chem. Minerals 39:1-15.

Gatta G.D., Merlini M., Lee Y., Poli S. (2011b) Behavior of epidote at high pressure and high temperature: a powder diffraction study up to $10 \mathrm{GPa}$ and 1,200 K. Phys. Chem. Minerals 38:419-428.

Gieré R, Sorensen SS (2004) Allanite and other REE-rich epidote-group minerals. In: Franz G, Liebscher A (eds), Epidotes, Vol. 56, p. 431-493. Reviews in Mineralogy and Geochemistry, Mineralogical Society of America and Geochemical Society, Washington, U.S.A..

Heinz DL, Jeanloz R (1984) The equation of state of the gold calibration standard. J Appl Phys 55:885-893.

Holdaway MJ (1972) Thermal stability of Al-Fe epidotes as a function of $f \mathrm{O}_{2}$ and Fe content. Contrib Min Petrol 37:307-340.

Holland TJB, Redfern SAT, Pawley AR (1996) Volume behaviour of hydrous minerals at high pressure and temperature: II. Compressibilities of lawsonite, zoisite, clinozoisite, and epidote. Am Mineral 81:341-348.

Klemd R (2004) Fluid inclusions in epidote minerals and fluid development in epidote-bearing rocks. In: Franz G, Liebscher A (eds), Epidotes, Vol. 56, p. 197-234. Reviews in Mineralogy and Geochemistry, Mineralogical Society of America and Geochemical Society, Washington, U.S.A..

Klotz S, Chervin J-C, Munsch P, Le Marchand G (2009) Hydrostatic limits of 11 pressure transmitting media. J Phys D: Appl Phys 42: 075413 (7pp).

Liebscher A (2004) Spectroscopy of epidote minerals. In: Franz G, Liebscher A (eds), Epidotes, Vol. 56, p. 125-170. Reviews in Mineralogy and Geochemistry, Mineralogical Society of America and Geochemical Society, Washington, U.S.A..

Liou JG (1973) Synthesis and stability relations of epidote, $\mathrm{Ca}_{2} \mathrm{Al}_{2} \mathrm{FeSi}_{3} \mathrm{O}_{12}(\mathrm{OH})$. J Petrol 14:381-413.

Mao HK, Xu J, Bell PM (1986) Calibration of the ruby pressure gauge to 800 kbar under quasi-hydrostatic conditions. J Geophys Res 91:4673-4676.

Pawley AR, Redfern SAT, Holland TJB (1996) Volume behaviour of hydrous minerals at high pressure and temperature: 1. Thermal expansion of lawsonite, zoisite, clinozoisite, and diaspore. Am Mineral 81:335-340.

Poli S, Schmidt MW (1998) The high-pressure stability of zoisite and phase relationships of zoisite-bearing assemblages. Contrib Mineral Petrol 130:162-175. 
523 (2016) High-pressure behavior of natural single-crystal epidote and clinozoisite up to 52440 GPa. Phys Chem Minerals 43:649-659.

525 Rothkirch A, Gatta GD, Meyer M, Merkel S, Merlini M, Liermann H-P (2013)

526 Single-crystal diffraction at the Extreme conditions beamline P02.2: procedure for 527 collecting and analyzing high-pressure single-crystal data. J Synchrotron Rad 20:711528720.

529 Schmidt MW, Poli S (2004) Magmatic epidotes. In G. Franz and A. Liebscher, 530 Eds., Epidotes, Vol. 56, p. 399-430. Reviews in Mineralogy and Geochemistry, 531 Mineralogical Society of America and Geochemical Society, Washington, U.S.A.

532 Sheldrick GM (1997) SHELX-97. Programs for crystal structure determination 533 and refinement. University of Göttingen, Germany.

534 Sheldrick GM (2008) A short history of SHELX. Acta Cryst A64:112-122. 
538 Table 1. Lattice parameters of allanite at different pressures, based on the two datasets 539 collected using the methanol:ethanol:water mix (HP-mew) and neon $(\mathrm{H} P-\mathrm{Ne})$ as $P$ -

540 transmitting fluids ( $P$-uncertainty: $\pm 0.1 \mathrm{GPa}$ )

541

542

\begin{tabular}{lcccccc}
\hline Experiment & $P(\mathrm{GPa})$ & $a(\AA)$ & $b(\AA)$ & $c(\AA)$ & $\beta(\AA)$ & $V\left(\AA^{3}\right)$ \\
\hline $\mathrm{H} P$-mew & 0.0001 & $8.9116(3)$ & $5.738(2)$ & $10.1447(4)$ & $114.979(4)$ & $470.2(2)$ \\
$\mathrm{H} P$-mew & 0.0001 & $8.9130(2)$ & $5.735(2)$ & $10.1484(3)$ & $114.993(3)$ & $470.2(2)$ \\
$\mathrm{H} P$-mew & 1.17 & $8.8882(4)$ & $5.719(2)$ & $10.1071(4)$ & $114.872(6)$ & $466.1(2)$ \\
$\mathrm{H} P$-mew & 1.60 & $8.8781(4)$ & $5.712(2)$ & $10.0911(3)$ & $114.832(5)$ & $464.42(9)$ \\
$\mathrm{H} P$-mew & 1.97 & $8.8718(4)$ & $5.707(2)$ & $10.0821(4)$ & $114.805(5)$ & $463.4(1)$ \\
$\mathrm{H} P$-mew & 2.81 & $8.8497(2)$ & $5.697(8)$ & $10.0509(2)$ & $114.707(3)$ & $460.33(7)$ \\
$\mathrm{H} P$-mew & 3.30 & $8.8416(4)$ & $5.6890(2)$ & $10.0383(4)$ & $114.684(5)$ & $458.8(1)$ \\
$\mathrm{H} P$-mew & 3.61 & $8.8325(3)$ & $5.6880(9)$ & $10.0293(3)$ & $114.647(3)$ & $457.96(7)$ \\
$\mathrm{H} P$-mew & 3.99 & $8.8223(2)$ & $5.6834(8)$ & $10.0152(2)$ & $114.593(3)$ & $456.62(7)$ \\
$\mathrm{H} P$-mew & 4.86 & $8.7996(3)$ & $5.674(1)$ & $9.9865(3)$ & $114.519(4)$ & $453.63(8)$ \\
$\mathrm{H} P$-mew & 5.08 & $8.7963(2)$ & $5.6686(9)$ & $9.9813(2)$ & $114.512(3)$ & $452.84(7)$ \\
$\mathrm{H} P$-mew & 5.55 & $8.7851(2)$ & $5.6657(9)$ & $9.9667(2)$ & $114.462(3)$ & $451.55(7)$ \\
$\mathrm{H} P$-mew & 6.45 & $8.7655(2)$ & $5.6550(9)$ & $9.9412(2)$ & $114.388(3)$ & $448.80(7)$ \\
$\mathrm{H} P$-mew & 7.07 & $8.7466(3)$ & $5.644(2)$ & $9.9177(3)$ & $114.321(4)$ & $446.2(1)$ \\
$\mathrm{H} P$-mew & 7.61 & $8.7384(3)$ & $5.638(2)$ & $9.9073(3)$ & $114.287(4)$ & $444.94(9)$ \\
$\mathrm{H} P$-mew & 8.51 & $8.7231(3)$ & $5.629(2)$ & $9.8817(3)$ & $114.225(4)$ & $442.50(9)$ \\
$\mathrm{H} P$ - $\mathrm{Ne}^{\mathrm{c}}$ & 1.39 & $8.8881(6)$ & $5.7303(3)$ & $10.111(2)$ & $114.88(2)$ & $467.2(2)$ \\
$\mathrm{H} P$ - $\mathrm{Ne}^{\mathrm{c}}$ & 9.90 & $8.668(3)$ & $5.6171(2)$ & $9.839(6)$ & $113.87(6)$ & $438.1(3)$ \\
$\mathrm{H} P$ - $\mathrm{Ne}^{\mathrm{c}}$ & 14.64 & $8.563(3)$ & $5.5643(2)$ & $9.722(7)$ & $113.56(7)$ & $424.6(4)$ \\
\hline
\end{tabular}

${ }^{\text {a }}$ Sample in the DAC without $P$-medium

bAfter decompression.

${ }^{\text {c}}$ For the experiments in $\mathrm{Ne}$, the $P$-value at any data point represents the average value obtained by the rubyfluorescence method and the BM-EoS fit based on the mew experiments. 
Table 2. Details pertaining to the data collections and structure refinements of allanite at different pressures $(P$-uncertainty: $\pm 0.1 \mathrm{GPa})$.

\begin{tabular}{|c|c|c|c|c|c|c|c|c|c|}
\hline$P(\mathrm{GPa})$ & $0.0001^{\mathrm{a}}$ & 1.17 & 1.60 & 1.97 & 3.61 & 3.99 & 4.86 & 5.08 & 5.55 \\
\hline$a(\AA)$ & $8.9116(3)$ & $8.8882(4)$ & $8.8781(4)$ & $8.8718(4)$ & $8.8325(3)$ & $8.8223(2)$ & $8.7996(3)$ & $8.8223(2)$ & $8.7996(3)$ \\
\hline$b(\AA)$ & $5.738(2)$ & $5.719(2)$ & $5.712(2)$ & $5.707(2)$ & $5.6880(9)$ & $5.6834(8)$ & $5.674(1)$ & $5.6834(8)$ & $5.674(1)$ \\
\hline$c(\AA)$ & $10.1447(4)$ & $10.1071(4)$ & $10.0911(3)$ & $10.0821(4)$ & $10.0293(3)$ & $10.0152(2)$ & $9.9865(3)$ & $10.0152(2)$ & $9.9865(3)$ \\
\hline$\beta(\AA)$ & 114.979(4) & $114.872(6)$ & $114.832(5)$ & $114.805(5)$ & $114.647(3)$ & $114.593(3)$ & $114.519(4)$ & $114.593(3)$ & $114.519(4)$ \\
\hline$V\left(\AA^{3}\right)$ & $470.2(2)$ & $466.1(2)$ & $464.42(9)$ & $463.4(2)$ & $457.96(7)$ & $456.62(7)$ & $453.63(8)$ & $456.62(7)$ & $453.65(8)$ \\
\hline Space group & $P 2_{1} / m$ & $P 2_{1} / m$ & $P 2_{1} / m$ & $P 2_{1} / m$ & $P 2_{1} / m$ & $P 2_{1} / m$ & $P 2_{1} / m$ & $P 2_{1} / m$ & $P 2_{1} / m$ \\
\hline$\lambda(\AA)$ & 0.28940 & 0.28940 & 0.28940 & 0.28940 & 0.28940 & 0.28940 & 0.28940 & 0.28940 & 0.28940 \\
\hline$\theta_{\max }\left({ }^{\circ}\right)$ & 18.08 & 17.99 & 18.01 & 18.02 & 18.10 & 18.11 & 18.15 & 18.11 & 18.15 \\
\hline No. measured reflections & 2272 & 2147 & 2186 & 2127 & 2137 & 2170 & 2020 & 2170 & 2020 \\
\hline No. unique reflections & 1106 & 1189 & 1185 & 1168 & 1148 & 1135 & 1059 & 1135 & 1059 \\
\hline $\begin{array}{l}\text { No. unique reflections with } \\
F_{\mathrm{o}}>4 \sigma\left(F_{o}\right)\end{array}$ & 1106 & 1189 & 1185 & 1168 & 1148 & 1135 & 1059 & 1135 & 1059 \\
\hline No. refined parameters & 66 & 63 & 63 & 63 & 63 & 63 & 63 & 63 & 63 \\
\hline$R_{\text {int }}$ & 0.0159 & 0.0189 & 0.0203 & 0.0221 & 0.0274 & 0.0207 & 0.0172 & 0.0207 & 0.0172 \\
\hline$R_{1}(F)$ with $F_{\mathrm{o}}>4 \sigma\left(F_{\mathrm{o}}\right)$ & 0.0356 & 0.0351 & 0.0396 & 0.0466 & 0.0452 & 0.0403 & 0.0404 & 0.0403 & 0.0404 \\
\hline $\mathrm{w} R_{2}\left(F^{2}\right)$ & 0.0952 & 0.0931 & 0.1046 & 0.1220 & 0.1229 & 0.1021 & 0.1057 & 0.1021 & 0.1057 \\
\hline GooF & 1.319 & 1.198 & 1.326 & 1.509 & 1.447 & 1.325 & 1.387 & 1.325 & 1.387 \\
\hline Residuals $\left(\mathrm{e}^{-} / \AA^{3}\right)$ & $-0.86 /+1.01$ & $-0.77 /+1.12$ & $-1.06 / 1.16$ & $-1.12 / 1.30$ & $-1.27 / 1.50$ & $-1.34 / 1.03$ & $-1.45 / 1.13$ & $-1.34 / 1.03$ & $-1.45 / 1.13$ \\
\hline$P(\mathrm{GPa})$ & 6.45 & 7.07 & 7.61 & 8.51 & $1.39^{\mathrm{b}}$ & $9.90^{b}$ & $14.64^{\mathrm{b}}$ & & \\
\hline$a(\AA)$ & $8.7655(2)$ & $8.7466(3)$ & $8.7384(3)$ & $8.7231(3)$ & $8.8881(6)$ & $8.668(3)$ & $8.563(3)$ & & \\
\hline$b(\AA)$ & $5.6550(9)$ & $5.644(2)$ & $5.638(2)$ & $5.6475(2)$ & $5.7303(3)$ & $5.6171(2)$ & $5.5643(2)$ & & \\
\hline$c(\AA)$ & $9.9412(2)$ & $9.9177(3)$ & $9.9073(3)$ & $9.8817(3)$ & $10.111(2)$ & $9.839(6)$ & $9.722(7)$ & & \\
\hline$\beta(\AA)$ & $114.388(3)$ & $114.321(4)$ & $114.287(4)$ & $114.225(4)$ & $114.88(2)$ & $113.87(6)$ & $113.56(7)$ & & \\
\hline$V(\AA 3)$ & $448.80(7)$ & $446.2(1)$ & $444.94(9)$ & $445.2(3)$ & $467.2(2)$ & $438.1(3)$ & $424.6(4)$ & & \\
\hline Space group & $P 2_{1} / m$ & $P 2_{1} / m$ & $P 2_{1} / m$ & $P 2_{1} / m$ & $P 2_{1} / m$ & $P 2_{1} / m$ & $P 2_{1} / m$ & & \\
\hline$\lambda(\AA)$ & 0.28940 & 0.28940 & 0.28940 & 0.28940 & 0.28940 & 0.28940 & 0.28940 & & \\
\hline$\theta_{\max }\left({ }^{\circ}\right)$ & 17.93 & 17.97 & 17.98 & 18.02 & 18.11 & 17.43 & 17.63 & & \\
\hline No. measured reflections & 1980 & 1834 & 2067 & 2158 & 1657 & 1432 & 1494 & & \\
\hline No. unique reflections & 1064 & 985 & 1053 & 1078 & 946 & 741 & 724 & & \\
\hline $\begin{array}{l}\text { No. unique reflections with } \\
F_{o}>4 \sigma\left(F_{o}\right)\end{array}$ & 1064 & 985 & 1053 & 1076 & 945 & 736 & 723 & & \\
\hline No. refined parameters & 63 & 63 & 63 & 63 & 63 & 63 & 64 & & \\
\hline$R_{\text {int }}$ & 0.0232 & 0.0225 & 0.0190 & 0.0209 & 0.0176 & 0.0244 & 0.0215 & & \\
\hline$R_{1}(F)$ with $F_{\mathrm{o}}>4 \sigma\left(F_{\mathrm{o}}\right)$ & 0.0421 & 0.0498 & 0.0385 & 0.0377 & 0.0442 & 0.0609 & 0.0479 & & \\
\hline $\mathrm{w} R_{2}\left(F^{2}\right)$ & 0.1072 & 0.1206 & 0.1000 & 0.0985 & 0.1107 & 0.1523 & 0.1195 & & \\
\hline GooF & 1.331 & 1.481 & 1.350 & 1.302 & 1.480 & 1.970 & 1.601 & & \\
\hline Residuals $\left(\mathrm{e}^{-} / \AA^{3}\right)$ & $-1.35 / 1.02$ & $-1.51 / 0.96$ & $-1.10 / 1.06$ & $-1.21 / 1.21$ & $-1.38 / 1.03$ & $-1.47 / 1.70$ & $-1.03 / 1.23$ & & \\
\hline
\end{tabular}


Table 3. Principal "diameters" $(\AA)$ of the 8-membered ring $(\mathrm{O} 6 \leftrightarrow \mathrm{O} 10, \mathrm{O} 3 \leftrightarrow \mathrm{O} 3, \mathrm{O} 6 \leftrightarrow \mathrm{O} 6$ and $\mathrm{O} 8 \leftrightarrow \mathrm{O} 8)$ and of the 5-membered one $(\mathrm{O} 3 \leftrightarrow \mathrm{O} 1, \mathrm{O} 6 \leftrightarrow \mathrm{O} 1$, $\mathrm{O} 9 \leftrightarrow \mathrm{O} 5)$ at different pressures $(P$-uncertainty: $\pm 0.1 \mathrm{GPa})$.

\begin{tabular}{lcccccccc} 
Experiment & $P(\mathrm{GPa})$ & $\mathrm{O} 6 \leftrightarrow \mathrm{O} 10$ & $\mathrm{O} 3 \leftrightarrow \mathrm{O} 3$ & $\mathrm{O} 6 \leftrightarrow \mathrm{O} 6$ & $\mathrm{O} 8 \leftrightarrow \mathrm{O} 8$ & $\mathrm{O} 3 \leftrightarrow \mathrm{O} 1$ & $\mathrm{O} 6 \leftrightarrow \mathrm{O} 1$ & $\mathrm{O} 9 \leftrightarrow \mathrm{O} 5$ \\
\hline $\mathrm{H} P$-mew & 0.0001 & $7.032(9)$ & $7.297(10)$ & $7.702(9)$ & $4.778(8)$ & $3.615(5)$ & $4.364(11)$ & $4.674(5)$ \\
$\mathrm{H} P$-mew & 1.17 & $7.011(10)$ & $7.251(14)$ & $7.677(7)$ & $4.707(8)$ & $3.606(5)$ & $4.352(15)$ & $4.672(5)$ \\
$\mathrm{H} P$-mew & 1.60 & $7.005(9)$ & $7.251(12)$ & $7.668(7)$ & $4.691(9)$ & $3.601(5)$ & $4.349(13)$ & $4.669(5)$ \\
$\mathrm{H} P$-mew & 1.97 & $7.001(12)$ & $7.245(10)$ & $7.660(9)$ & $4.682(11)$ & $3.596(6)$ & $4.347(13)$ & $4.672(6)$ \\
$\mathrm{H} P$-mew & 3.61 & $6.971(8)$ & $7.198(8)$ & $7.637(9)$ & $4.624(10)$ & $3.581(5)$ & $4.338(9)$ & $4.671(6)$ \\
$\mathrm{H} P$-mew & 3.99 & $6.968(7)$ & $7.184(8)$ & $7.631(7)$ & $4.619(9)$ & $3.579(5)$ & $4.337(9)$ & $4.655(5)$ \\
$\mathrm{H} P$-mew & 4.86 & $6.951(9)$ & $7.162(10)$ & $7.612(9)$ & $4.587(9)$ & $3.571(5)$ & $4.332(11)$ & $4.652(5)$ \\
$\mathrm{H} P$-mew & 5.08 & $6.948(8)$ & $7.159(8)$ & $7.612(9)$ & $4.581(10)$ & $3.568(5)$ & $4.334(9)$ & $4.657(6)$ \\
$\mathrm{H} P$-mew & 5.55 & $6.942(8)$ & $7.146(8)$ & $7.610(9)$ & $4.560(10)$ & $3.563(5)$ & $4.326(9)$ & $4.651(6)$ \\
$\mathrm{H} P$-mew & 6.45 & $6.925(8)$ & $7.131(8)$ & $7.592(9)$ & $4.538(9)$ & $3.554(5)$ & $4.321(9)$ & $4.649(6)$ \\
$\mathrm{H} P$-mew & 7.07 & $6.912(10)$ & $7.119(11)$ & $7.579(10)$ & $4.515(11)$ & $3.543(6)$ & $4.314(12)$ & $4.644(7)$ \\
$\mathrm{H} P$-mew & 7.61 & $6.901(8)$ & $7.114(10)$ & $7.566(9)$ & $4.502(9)$ & $3.539(4)$ & $4.314(11)$ & $4.644(5)$ \\
$\mathrm{H} P$-mew & 8.51 & $6.883(8)$ & $7.101(10)$ & $7.547(7)$ & $4.478(9)$ & $3.531(4)$ & $4.309(11)$ & $4.643(5)$ \\
\hline
\end{tabular}

${ }^{\text {a}}$ Sample in the DAC without $P$-medium 
Table 4. Compressional parameters of allanite obtained by second- and third-order Birch-Murnaghan Equation of State fits (see text for details).

\begin{tabular}{ccccc}
\hline & $V_{0}, l_{0}\left(\AA^{3,} \AA\right)$ & $K_{\mathrm{P} 0, \mathrm{~T} 0}(\mathrm{GPa})$ & $K^{\prime}$ & $E o S$ order \\
\hline$V_{0}$ & $470.6(2)$ & $122(1)$ & 4 (fixed) & $2^{\text {nd }}$ order \\
$a_{0}$ & $8.918(3)$ & $114(2)$ & 4 (fixed) & $2^{\text {nd }}$ order \\
$b_{0}$ & $5.735(2)$ & $140(4)$ & 4 (fixed) & $2^{\text {nd }}$ order \\
$c_{0}$ & $10.149(2)$ & $92(1)$ & 4 (fixed) & $2^{\text {nd }}$ order \\
$V_{0}$ & $470.2(2)$ & $131(4)$ & $1.9(8)$ & $3^{\text {rd }}$ order \\
\hline
\end{tabular}


Figure 1. Crystal structure of allanite viewed down [010] and [001], and overlying unit-strain ellipsoid based on Eulerian finite strain calculated between ambient pressure and $8.51 \mathrm{GPa}[\varepsilon 2 / / b, \quad \varepsilon 1$ and $\varepsilon 3$ lying in the (010)-plane, $\varepsilon 1 \angle a=136.6(2)^{\circ} ; \varepsilon 1=-0.02849(5), \varepsilon 2=-0.0192(5)$, and $\varepsilon 3=-0.01306(8) \mathrm{GPa}^{-1}$, $\varepsilon 1: \varepsilon 2: \varepsilon 3=2.18: 1.47: 1]$. Si-tetrahedra (coordinated by Si1, Si2 and Si3 sites) and $\mathrm{Al} / \mathrm{Fe}$-octahedra (coordinated by the $M 1, M 2$ and $M 3$ sites) are shown as closed-faces polyhedra; large spheres represent the $A 1$ and $A 2$-sites. The 8-membered ring of polyhedra (with the diameters $O 3 \leftrightarrow 03, O 10 \leftrightarrow 06, O 6 \leftrightarrow O 6$ and $O 8 \leftrightarrow O 8$ ) and the 5membered ring (with the diameters $O 3 \leftrightarrow O 1, O 1 \leftrightarrow O 6$ and $O 9 \leftrightarrow 05$ ) are also shown (see text for further details).

Figure 2. Evolution of the lattice parameters of allanite with $P$ (GPa). (a) For the unitcell volume, the solid lines represent the third-order BM-EoS fits. The axial compressional behaviours of (b) allanite (this study), (c) epidotes with $0.74 \mathrm{Fe}$ a.p.f.u. (Gatta et al. 2011b), (d) epidotes with 0.79 Fe a.p.f.u. (Qin et al. 2016), and (e) clinozoisite with $0.40 \mathrm{Fe}$ a.p.f.u. (Qin et al. 2016) are also shown.

a)

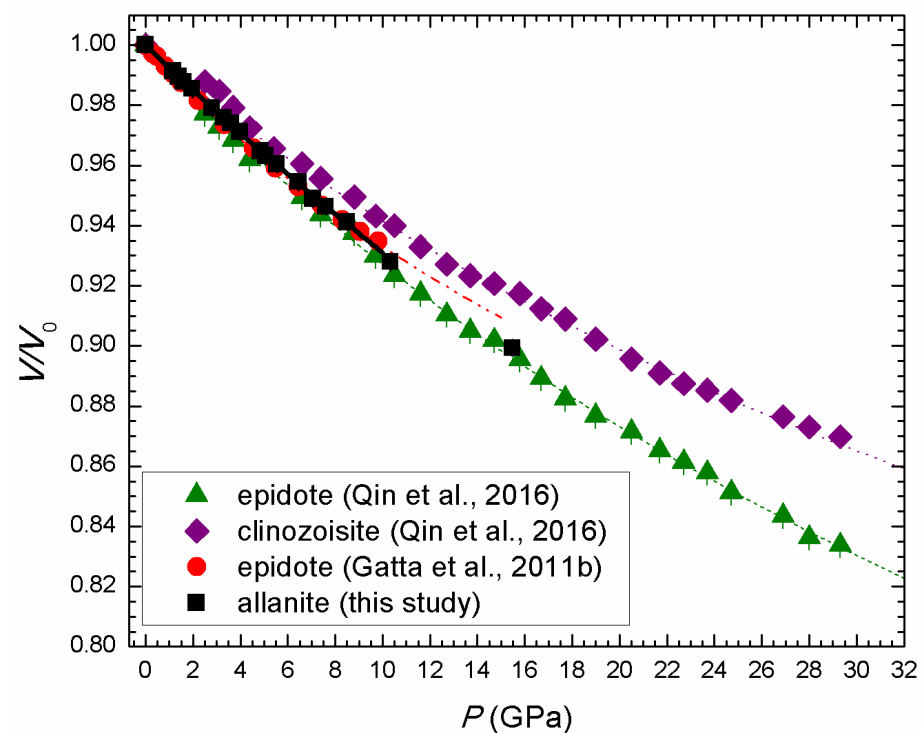

b)



d)

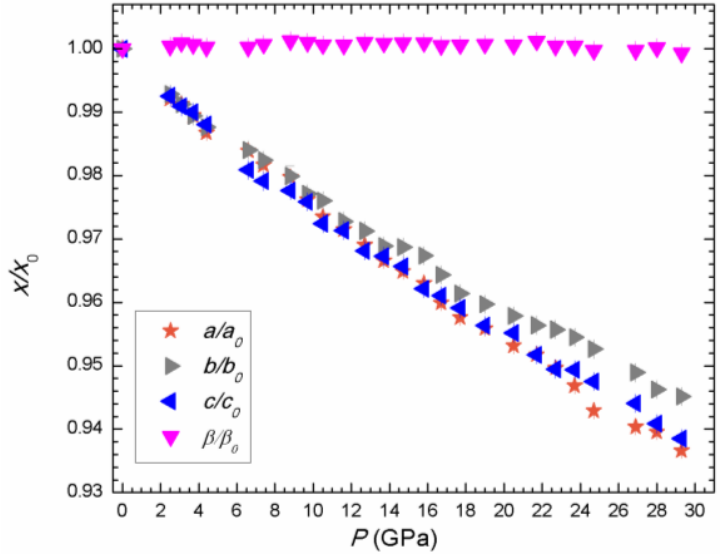

c)

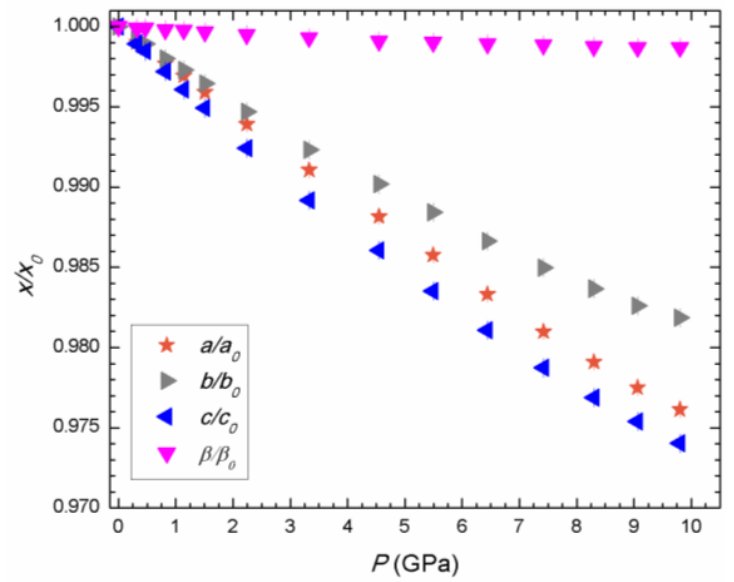

e)

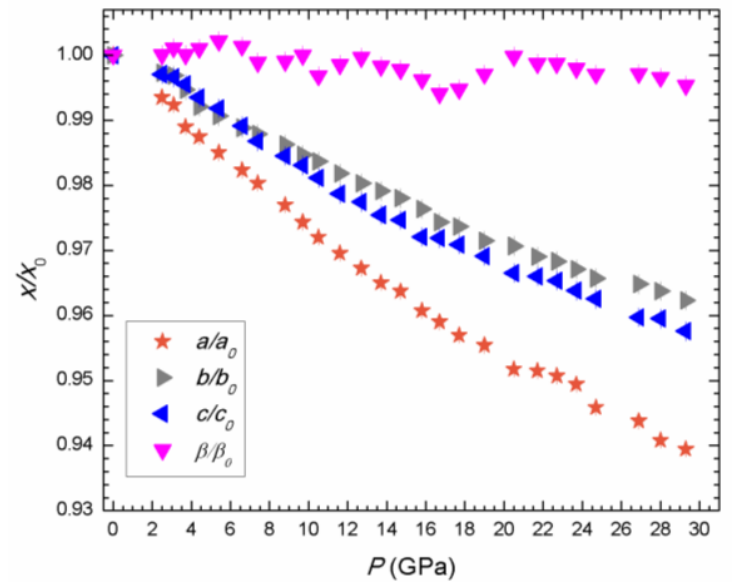


Figure 3. Normalized stress $\left(F e=P /\left[3 f e(1+2 f e)^{5 / 2}\right]\right) v s$. Eulerian finite strain $(f e=$ $\left.\left[\left(V_{0} / V\right)^{2 / 3}-1\right] / 2\right)$ plot. The $e s d s$ have been calculated according to Heinz and Jeanloz (1984). The solid line is a weighted linear fit through the data.

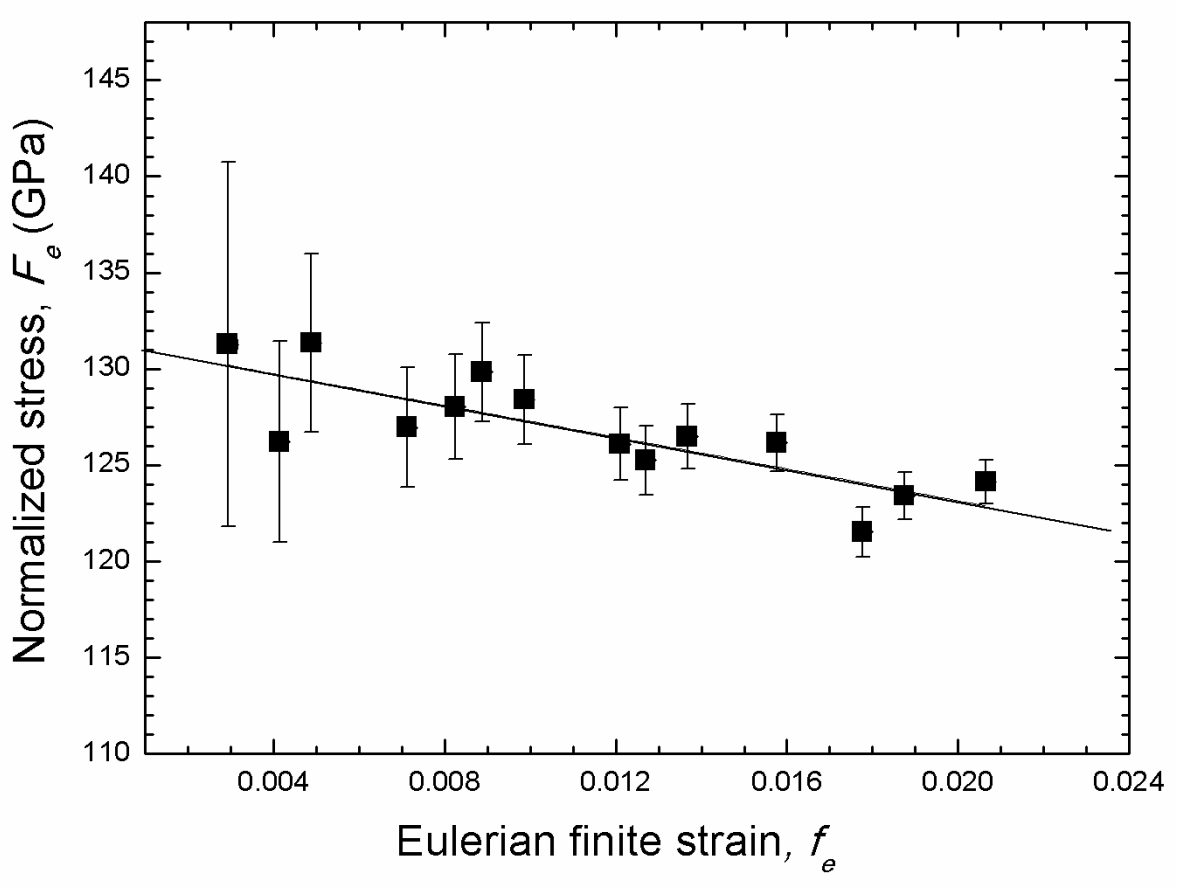


Figure 4. Confidence ellipses at $68.3 \%$ level $\left(\Delta \chi^{2}=2.30, \pm 1 \sigma\right.$, solid black line), $95.4 \%$ level $\left(\Delta \chi^{2}=6.17, \pm 2 \sigma\right.$, dashed black line $)$ and 99.7\% level $\left(\Delta \chi^{2}=11.8, \pm 3 \sigma\right.$, dotted black line) calculated starting from the variance-covariance matrix of $K_{\mathrm{P} 0, \mathrm{~T} 0}$ and $K^{\prime}$ obtained from the least-square procedure. The $K_{\mathrm{P} 0, \mathrm{~T} 0}$ and $K^{\prime}$ of Gatta et al. (2011b) for epidote (0.74 Fe a.p.f.u.; red circle), of Qin et al. (2016) for epidote $(0.79 \mathrm{Fe}$ a.p.f.u.; dark green triangle), and of Qin et al. (2016) for clinozoisite (0.40 Fe a.p.f.u.; purple diamond) are added for comparison (see text for further details). Error bars: \pm 1 esds.

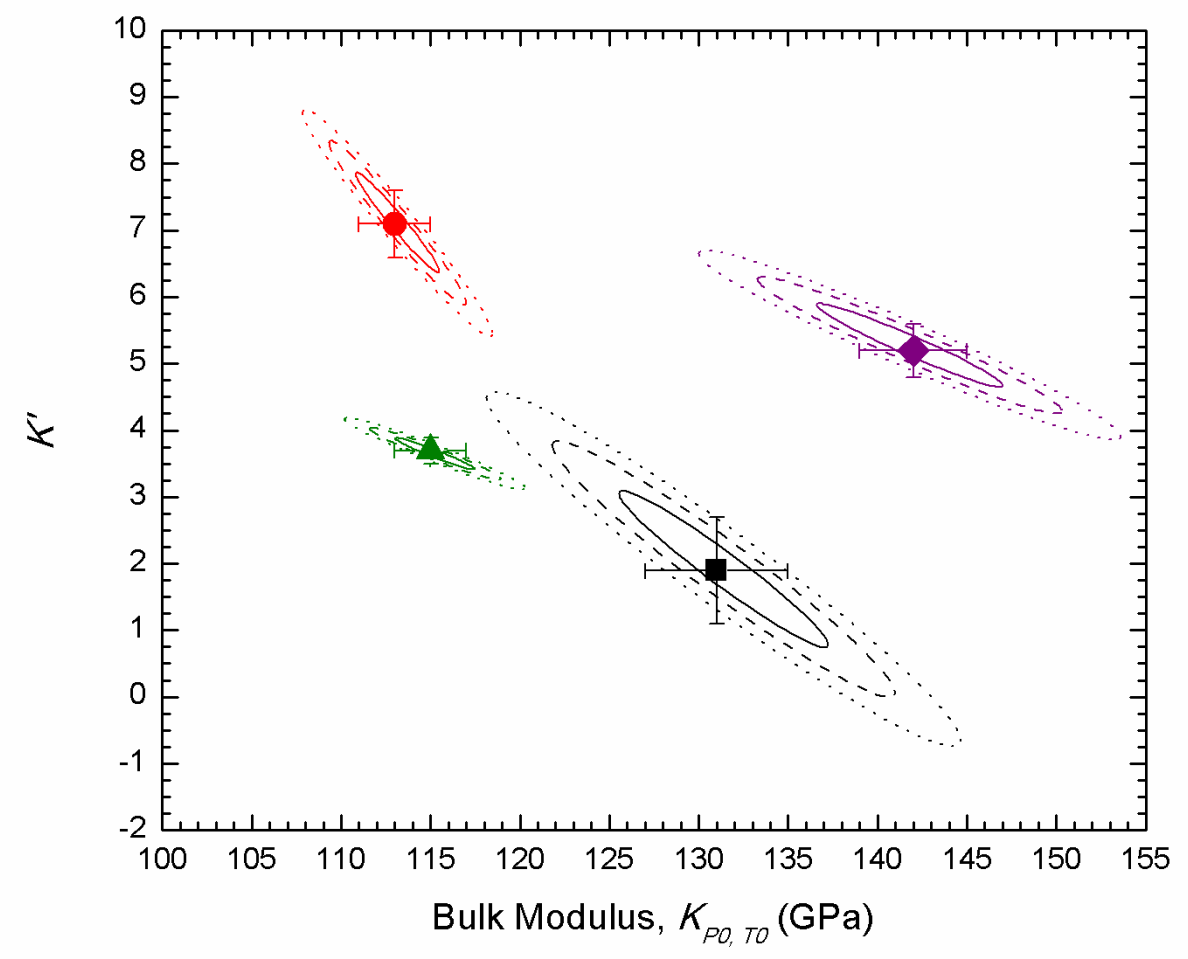


Figure 5. Evolution with $P$ of the (normalised) $\mathrm{O} 3 \leftrightarrow \mathrm{O} 3, \mathrm{O} 6 \leftrightarrow \mathrm{O} 6, \mathrm{O} 8 \leftrightarrow \mathrm{O} 8$ and $\mathrm{O} 10 \leftrightarrow \mathrm{O} 6$ "diameters" of the 8-membered ring of polyhedra, and of the $\mathrm{O} 3 \leftrightarrow \mathrm{O} 1$, $\mathrm{O} 1 \leftrightarrow \mathrm{O} 6$ and $\mathrm{O} 9 \leftrightarrow \mathrm{O} 5$ "diameters" of the 5-membered ring (see Fig. 1 and text for further details).
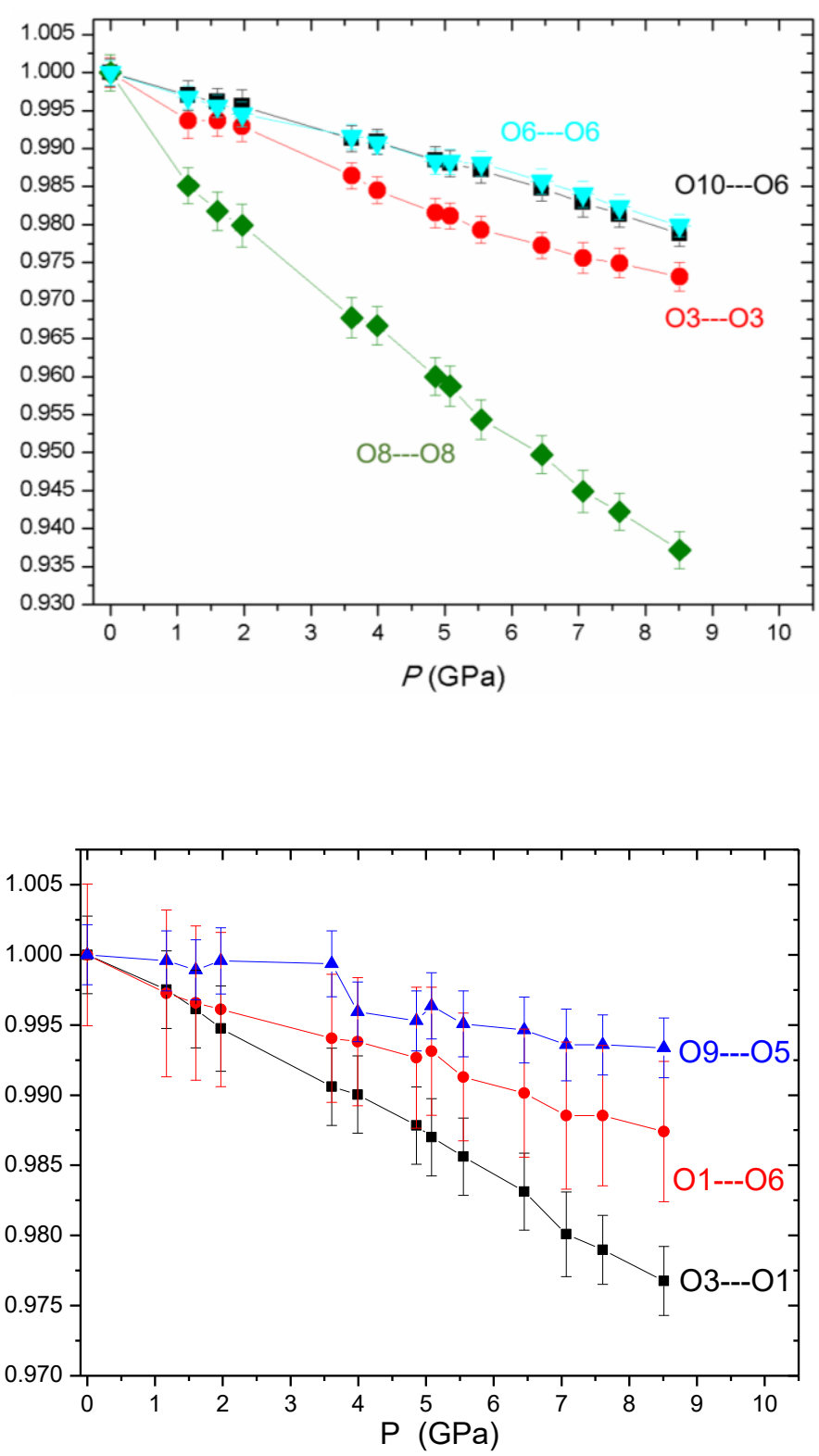